\title{
Recommendations for Nuclear Medicine Technologists Drawn from an Analysis of Errors Reported in Australian Radiation Incident Registers
}

\author{
Nicole Kearney $^{1}$ and Gary Denham ${ }^{2}$ \\ ${ }^{1}$ Department of Nuclear Medicine and PET, Hunter New England Imaging, Newcastle, NSW, Australia; and ${ }^{2}$ Department of \\ Radiology, Manning Rural Referral Hospital, Taree, NSW, Australia
}

When a radiation incident occurs in nuclear medicine in Australia, the incident is reported to the relevant state or territory authority, which performs an investigation and sends its findings to the Australian Radiation Protection and Nuclear Safety Agency. The agency then includes these data in its Australian Radiation Incident Register and makes them available to the public as an annual summary report on its website. The aim of this study was to analyze the radiation incidents included in these annual reports and in the publically available state and territory registers, identify any recurring themes, and make recommendations to minimize future incidents. Methods: A multidisciplinary team comprising a nuclear medicine technologist, a radiation therapist, and a diagnostic radiographer analyzed all nuclear medicine technology-, radiation therapy-, and diagnostic radiography-related incidents recorded in the Australian Radiation Incident Register and in the registers of New South Wales, Western Australia, Victoria, South Australia, and Tasmania between 2003 and 2015. Each incident was placed into 1 of 18 categories, and each category was examined to determine any recurring causes of the incidents. Results: We analyzed 209 nuclear medicine incidents. Their primary cause was failure to comply with time-out protocols (85.6\%). By analyzing both the causes and the rates of radiation incidents, we were able to recommend ways to help prevent them from being repeated. Conclusion: Information drawn from the Australian Radiation Incident Register and 5 state registers has revealed steps that can be taken by any nuclear medicine department to prevent repetition of the incidents that have already occurred.

Key Words: adverse events; incident reporting; patient safety; radiation safety

J Nucl Med Technol 2016; 44:243-247

DOI: $10.2967 /$ jnmt.116.178517

$\mathbf{T}$ wo articles published in 2000 paved the way for worldwide change in the quality in health care, bringing forward

Received May 18, 2016; revision accepted Aug. 10, 2016.

For correspondence or reprints contact: Nicole Kearney, Department of Nuclear Medicine and PET, Hunter New England Imaging, John Hunter Hospital, Locked Bag No. 1, HRMC, NSW 2310, Australia.

E-mail: nicole.kearney@hnehealth.nsw.gov.au

Published online Sep. 15, 2016.

COPYRIGHT (c) 2016 by the Society of Nuclear Medicine and Molecular Imaging, Inc. the notion that identifying and reporting errors will lead to improved overall efficiency and patient safety $(1,2)$.

There is evidence of increased rates of radiation-induced cancer in patients receiving cumulative doses above $100 \mathrm{mSv}$ (3). It is therefore the responsibility of the nuclear medicine professional not to become complacent about trying to minimize incidents and trying to keep patient doses as low as reasonably achievable. The potential risks associated with increased exposure to radiation highlight the importance of identifying, reporting, and analyzing errors within the profession (4).

A radiation incident is classified as an event that results in or has the potential to result in unplanned exposure to radiation when an ionizing radiation apparatus or radioactive substance is used (5). When radiation incidents occur in Australia, they are reported to the relevant state or territory authority, which performs an investigation and reports its findings to the Australian Radiation Protection and Nuclear Safety Agency. The agency then compiles these data and includes them in the Australian Radiation Incident Register.

The objectives of the Australian Radiation Incident Register are to highlight the causes of potential hazards, provide information on the incidents that have occurred, provide guidance to users of radiation to limit accidents, and provide data to other regulatory and advisory bodies. The agency includes incident data in its Australian Radiation Incident Register and makes them available to the public as an annual summary report on its website (6). The agency is intent on including in its future reports more information on postincident follow-up and the lessons learned (7).

This article is part of a larger project involving researchers from all 3 branches of the medical radiation science profession (nuclear medicine technology, radiation therapy, and diagnostic radiography) to determine what lessons can be learned from the errors that have been reported to state and territory radiation protection authorities.

Although nuclear medicine errors in Australia are well documented $(8-10)$, little is known about the lessons that can be learned from the errors that have been reported and made available to the public on radiation incident registers. The aim of this study was to analyze the radiation 
incidents included in these registers, identify any recurring themes, and make recommendations to minimize future incidents.

\section{MATERIALS AND METHODS}

A multidisciplinary team comprising a nuclear medicine technologist, a radiation therapist, and a diagnostic radiographer analyzed all nuclear medicine technology-, radiation therapy-, and diagnostic radiography-related incidents recorded in the Australian Radiation Incident Register and in the registers of New South Wales, Western Australia, Victoria, South Australia, and Tasmania between 2003 and 2015. Ethics approval was not required for the study, as only registers containing publically available anonymized data were examined.

This study used an error-classification type of taxonomy (11). Incidents that were deemed beyond the control of the practitioner (nuclear medicine technologist, diagnostic radiographer, or radiation therapist) were excluded from the study, along with incidents that did not contain enough information to allow the exact cause to be deciphered. All incidents were categorized by professional group and examined by the multidisciplinary team. Each member of the team ascertained the cause of every incident, and when there was disagreement as to the cause, the group discussed the incident in depth to derive a consensus. The 2012 and 2013 annual reports for the Australian Radiation Incident Register documented that approximately $70 \%$ of incidents were due to human error $(12,13)$. Although it can be argued that all incidents are caused by human error, this study aimed to perform a more in-depth analysis from which to draw specific recommendations. The incidents were therefore categorized further. Each nuclear medicine technology incident was placed into 1 of 18 categories (Table 1). Each category was then examined in greater detail to determine any recurring causes.

\section{RESULTS}

The New South Wales register included incidents from 2003 to 2013 (14); the Western Australia register, from 2004 to 2012 (15); the Victorian register, from 2007 to 2014 (16); the South Australian register, from 2004 to 2015 (17); and the Tasmania register, for the 2013-2014 financial year (18). The incidents were obtained from the annual reports of the New South Wales Environment Protection Authority, the Western Australian Radiologic Council, the Victorian Department of Health, the South Australian Environmental Protection Authority, and the Tasmanian Department of Health and Human Services, respectively.

Of the 573 incidents listed, 43 in the state registers were duplicated in the Australian Radiation Incident Register, leaving 530 to be analyzed. These were categorized by professional group: 209 (39\%) from nuclear medicine technology, 243 (46\%) from diagnostic radiography, and $78(15 \%)$ from radiation therapy. Table 1 defines the categories, and Table 2 provides the number of incidents in each. No trend was observed in the number of reported incidents per year.

At the time of a patient interview and immediately before a procedure is performed, a "time out" is called for a final team check of "correct patient, correct site, correct procedure." As shown in Table 2, the primary cause of radiation incidents in nuclear medicine in Australia was failure to comply with these time-out protocols (TOPs (19)), accounting for $85.6 \%$ of all incidents. This percentage includes both the patient interview TOP $(12.4 \%)$ and the procedural TOP $(73.2 \%)$. Booking errors caused $4.3 \%$ of all incidents, and the remaining $10.0 \%$ of incidents were classified as "other."

Nuclear medicine technology and radiation therapy had a higher percentage of procedural TOP errors than did diagnostic radiography. Diagnostic radiography had higher percentage of booking errors and patient interview TOP errors than did either nuclear medicine technology or radiation therapy.

Drawing from all the analyzed information, we were able to make recommendations to help prevent incidents from being repeated.

\section{DISCUSSION}

Failure to comply with the procedural TOP accounted for $73.2 \%$ of all incidents in this study. Two of the most significant contributors to this percentage were incorrect radiopharmaceutical $(36.4 \%)$ and incorrect dose (7.2\%), the combination of which accounted for $43.6 \%$ of all incidents. These results are comparable to those of a 2005 study by Martin et al. finding that $47 \%$ of radiation incidents in nuclear medicine were due to administration of the incorrect radiopharmaceutical or incorrect dose (20). Those authors had examined incident reporting and investigation systems in Scotland over a 10-y period. Hence, despite the advances in technology, the percentage of incidents due to administration of the incorrect radiopharmaceutical or dose has not changed over the last 2 decades. We believe these issues can be prevented by, first, requiring extensive radiopharmacy laboratory training by experienced technologists for new staff members and, second, implementing an integrated radiopharmacy-management software package to reduce the risk of incorrect reconstitution or dosing of the radiopharmaceutical. Such software packages connect directly to an ionizing chamber (dose calibrator) and bar code reader, enabling complete traceability of every activity that occurs in the radiopharmacy laboratory, from receipt of the pharmaceutical inventory to dispensation of each dose. However, the overall issue of incorrect radiopharmaceutical and dose administration can be suitably addressed only through a coordinated approach by the entire profession, including nuclear medicine societies, the Australian Radiation Protection and Nuclear Safety Agency, universities, and radiopharmacy management.

Two incidents were due to dispensation of the incorrect dose to children because their weight had not been estimated correctly. Weight estimation is used in emergency settings when trauma or pain prevent weighing of the child and active resuscitation is required. The formula given in the Advanced 
TABLE 1

Definitions of Errors

\begin{tabular}{|c|c|c|c|}
\hline Error type & Category & Subcategory & Definition \\
\hline \multirow[t]{12}{*}{ TOP noncompliance } & Patient interview TOP & $\begin{array}{l}\text { Questions } \\
\text { noncompliance }\end{array}$ & $\begin{array}{l}\text { Failure to ask "correct patient, correct site, correct } \\
\text { procedure" questions }\end{array}$ \\
\hline & & Request form & $\begin{array}{l}\text { Errors due to incorrect patient details on request } \\
\text { form (e.g., wrong patient sticker) }\end{array}$ \\
\hline & & $\begin{array}{l}\text { Pregnancy/ } \\
\text { breastfeeding }\end{array}$ & $\begin{array}{l}\text { Errors due to failure to check for pregnancy and } \\
\text { breastfeeding }\end{array}$ \\
\hline & Procedural TOP & Handover & $\begin{array}{l}\text { Procedure performed incorrectly because first person } \\
\text { fails to properly hand over patient to second person } \\
\text { (e.g., provides inadequate information) or second } \\
\text { person fails to make appropriate checks }\end{array}$ \\
\hline & & Staff & $\begin{array}{l}\text { Procedure performed incorrectly because of human } \\
\text { error (e.g., radiographer forgets to connect pressure } \\
\text { injector to patient's cannula) }\end{array}$ \\
\hline & & Internal systems & $\begin{array}{l}\text { Procedure performed incorrectly because of errors } \\
\text { in procedures or systems within the department }\end{array}$ \\
\hline & & Procedure matching & $\begin{array}{l}\text { Errors due to failure to match patient presentation } \\
\text { to procedure on request form }\end{array}$ \\
\hline & & Dose & Errors due to administration of incorrect dose \\
\hline & & Radiopharmaceutical & $\begin{array}{l}\text { Errors due to administration of incorrect } \\
\text { radiopharmaceutical }\end{array}$ \\
\hline & & Intravenous access & Errors due to lack of proper intravenous access \\
\hline & & Request form & $\begin{array}{l}\text { Procedure performed incorrectly because request form } \\
\text { was ambiguous }\end{array}$ \\
\hline & & Quality control & $\begin{array}{l}\text { Procedure performed incorrectly because staff failed } \\
\text { to complete quality control test }\end{array}$ \\
\hline \multirow[t]{2}{*}{ Booking errors } & $\begin{array}{l}\text { Internal and } \\
\text { external systems }\end{array}$ & & $\begin{array}{l}\text { Booking errors before patient reaches MRS personnel, } \\
\text { due to systems outside department (e.g., electronic } \\
\text { x-ray requests) or within department (e.g., reception) }\end{array}$ \\
\hline & Request form & & $\begin{array}{l}\text { Booking errors due to use of duplicate or nonoriginal } \\
\text { request form }\end{array}$ \\
\hline \multirow[t]{4}{*}{ Other errors } & $\begin{array}{l}\text { Students/new } \\
\text { graduates }\end{array}$ & & $\begin{array}{l}\text { Errors by students or new graduates due to inadequate } \\
\text { supervision by MRS personnel }\end{array}$ \\
\hline & Training & & $\begin{array}{l}\text { Errors due to inadequate training on software, } \\
\text { equipment, or procedures }\end{array}$ \\
\hline & Exposure to radiation & & $\begin{array}{l}\text { Errors causing the staff or the public to unintentionally } \\
\text { be exposed to radiation }\end{array}$ \\
\hline & $\begin{array}{l}\text { Radiopharmaceutical } \\
\text { spillage }\end{array}$ & & $\begin{array}{l}\text { Errors causing a radiopharmaceutical to unintentionally } \\
\text { be spilled }\end{array}$ \\
\hline
\end{tabular}

$\mathrm{MRS}=$ medical radiation science

Pediatric Life Support course, which is taken throughout Europe, South Africa, Australia, and New Zealand, is weight (in $\mathrm{kg})=(3 \times$ age [in years] $)+7$, and we recommend that technologists become familiar with this formula (21). We also recommend that pediatric doses be calculated according to the European Association of Nuclear Medicine dosage card (22) or the Society of Nuclear Medicine and Molecular Imaging procedure standard (23).

Noncompliance with the procedural TOP caused $7.2 \%$ of the incidents. These incidents would have been prevented if the TOP had been followed. We recommend that the nuclear medicine staff be educated on all procedures during initial orientation, have ready access to written protocols for all procedures, and be involved in regular reviews and updates. Quality improvement projects such as regularly scheduled protocol reviews can be used to help the staff keep abreast of innovations in the profession. Continuing professional development is a requirement of certification, and the time and effort put toward protocol review contribute to the professional development and overall expertise of a nuclear medicine technologist.

Remarkably, more than $12 \%$ of errors were due to noncompliance with the patient interview TOP. The incident registers specifically stated that the nuclear medicine technologist did not, for example, perform the pregnancy/ breastfeeding check. The TOP (19) is designed to provide a nationally consistent method for ensuring the intended procedure is performed on the correct patient (24). TOPs in radiology, nuclear medicine, and radiation therapy were released in 2008, but unlike those produced for the operating room, these were not mandated by health ministers. Matching of the patient presentation with the requested 
TABLE 2

Number of Incidents

\begin{tabular}{cc}
\hline Error type & Incidents $(n)$ \\
\hline TOP noncompliance & $179(85.6 \%)$ \\
Patient interview TOP & $26(12.4 \%)$ \\
\hline Noncompliance & $19(9.1 \%)$ \\
\hline Errors in request form & $5(2.4 \%)$ \\
Failure to check for & $2(1.0 \%)$ \\
pregnancy/breastfeeding & \\
\hline Procedural TOP & $153(73.2 \%)$ \\
Handover error & $4(1.9 \%)$ \\
Staff error & $14(6.7 \%)$ \\
Errors in internal systems & $3(1.4 \%)$ \\
Lack of procedure matching & $15(7.2 \%)$ \\
Incorrect dose & $15(7.2 \%)$ \\
\hline Incorrect radiopharmaceutical & $76(36.4 \%)$ \\
Lack of intravenous access & $19(9.1 \%)$ \\
Request form ambiguity & $3(1.4 \%)$ \\
Lack of quality control & $4(1.9 \%)$ \\
Booking errors & $9(4.3 \%)$ \\
Errors in internal or external systems & $5(2.4 \%)$ \\
\hline Use of nonoriginal request form & $4(1.9 \%)$ \\
Other errors & $21(10.0 \%)$ \\
Inadequate student/new-graduate & $6(2.9 \%)$ \\
supervision & \\
Inadequate training & $4(1.9 \%)$ \\
Exposure of staff or public to radiation & $1(0.5 \%)$ \\
Spillage of radiopharmaceutical & $10(4.8 \%)$ \\
Total & 209 \\
\hline
\end{tabular}

procedure is part of the National Safety and Quality Health Service Standards, which are a critical component of the Australian Health Service Safety and Quality Accreditation Scheme endorsed by the Australian health ministers in November 2010 (25). A 2011 study by Danaher et al. reviewed the validity of implementing a patient identification procedure in radiology departments and found that significant systems improvements could be achieved. The authors acknowledged that improvements in staff performance might be attributable to the Hawthorne effect (26) - a reference to the tendency of subjects to improve their behavior when they know they are being observed (27). We recommend that staff be well educated on TOPs and that the staff be audited and observed by management.

Inadequate supervision of students and new graduates led to $2.9 \%$ of all incidents in this study. Such incidents are easily prevented, as all radiation-licensed nuclear medicine technologists should be aware of their professional responsibility of supervising students at all times and the potential repercussions of complacency.

Among the publically available radiation incident state registers identified in this study, the Western Australia and Victorian registers contained far more detailed information than the Australian Radiation Incident Register annual reports, and the New South Wales register generally contained more information than the Australian Radiation Incident Register annual reports. Because access to more
TABLE 3

Recommendations to Prevent Incidents

\begin{tabular}{|c|c|}
\hline Category & Recommendation \\
\hline Radiopharmacy training & $\begin{array}{l}\text { Provide extensive training } \\
\text { for new staff members }\end{array}$ \\
\hline $\begin{array}{l}\text { Radiopharmacy } \\
\text { management }\end{array}$ & $\begin{array}{l}\text { Implement integrated software } \\
\text { packages }\end{array}$ \\
\hline $\begin{array}{l}\text { Radiopharmaceutical } \\
\text { administration and dose }\end{array}$ & $\begin{array}{l}\text { Use coordinated approach } \\
\text { in which all nuclear medicine } \\
\text { professionals address } \\
\text { administration and dose errors }\end{array}$ \\
\hline $\begin{array}{l}\text { Pediatric dosing and } \\
\text { weight estimation }\end{array}$ & $\begin{array}{l}\text { Use correct calculators and } \\
\text { formulas }\end{array}$ \\
\hline Departmental protocols & $\begin{array}{l}\text { Provide in writing, regularly } \\
\text { update, and keep readily } \\
\text { accessible }\end{array}$ \\
\hline Education & $\begin{array}{l}\text { Teach TOP to all staff and audit } \\
\text { for compliance }\end{array}$ \\
\hline Students/new graduates & Improve supervision \\
\hline Error reporting & Remove disincentives \\
\hline Safety & $\begin{array}{l}\text { Create culture of safety } \\
\text { throughout department }\end{array}$ \\
\hline
\end{tabular}

information about the cause of an incident is beneficial when attempting to learn from past mistakes, changes to the way the information is presented in the Australian Radiation Incident Register annual reports may be warranted.

Although this study dealt with reported errors, underreporting is an inherent issue in the field of nuclear medicine $(10,28)$, as in the medical field as a whole (29). Some have suggested that nuclear medicine departments in New South Wales whose medical physicists have served on the New South Wales Radiation Advisory Council would be more likely to report a radiation incident because they better understand the regulatory process. This process itself contributes to underreporting because the reporting requirements vary by Australian jurisdiction (28). Nuclear medicine departments worldwide have to create a culture of safety if the profession is to reduce the number of errors and near misses reported and learn how to prevent radiation incidents (30). Disincentives to the reporting of errors, such as punitive systems, must first be removed if underreporting is ever to be eliminated (31).

Table 3 summarizes our recommendations.

\section{CONCLUSION}

Regulatory requirements should always be met in all areas of medical radiation science, but it is also the responsibility of individual professionals to establish a radiation safety ethos in their workplace. This can be achieved by fostering positive change and creating a culture of safety for all staff and patients. By analyzing both the cause and the rate of radiation incidents from the Australian Radiation Incident Register and state registers, we have found that various steps can be recommended to prevent repetition of the incidents that have already occurred. These recommendations, or system improvements, can be 
implemented by all nuclear medicine departments irrespective of their size or location.

\section{DISCLOSURE}

No potential conflict of interest relevant to this article was reported.

\section{ACKNOWLEDGMENTS}

We acknowledge the assistance of Nicole Page, Radiation Therapy Department, Calvary Mater Hospital, Waratah, NSW, and Dr. Sandeep Gupta, Department of Nuclear Medicine and PET, Hunter New England Imaging, Newcastle, NSW.

\section{REFERENCES}

1. Kohn LT, Corrigan JM, Donaldson MS, eds. To Err Is Human: Building a Safer Health System. Washington, DC: National Academies Press; 2000.

2. Department of Health. An Organisation with a Memory: Report of an Expert Group on Learning from Adverse Events in the NHS. London, UK: Her Majesty's Stationery Office; 2000.

3. Committee to Assess Health Risks from Exposure to Low Levels of Ionizing Radiation, Board on Radiation Effects Research, Division on Earth and Life Studies, National Research Council. Health Risks from Exposure to Low Levels of Ionizing Radiation: BEIR VII Phase 2. Washington, DC: National Academies Press; 2006.

4. Cardis E, Vrijheid M, Blettner M, et al. Risk of cancer after low doses of ionising radiation: retrospective cohort study in 15 countries. BMJ. 2005;331:77-82.

5. National Directory for Radiation Protection, republished February 2014, including amendments 1-6. Australian Radiation Protection and Nuclear Safety Agency website. http://www.arpansa.gov.au/pubs/rps/rps6_6.pdf. Accessed August 30, 2016.

6. Annual summary reports of the Australian Radiation Incident Register. Australian Radiation Protection and Nuclear Safety Agency website. http://www.arpansa.gov. au/radiationprotection/arir/arir-reports.cfm. Accessed August 30, 2016.

7. The Australian Radiation Incident Register. Australian Radiation Protection and Nuclear Safety Agency website. http://www.arpansa.gov.au/RadiationProtection/ arir/index.cfm. Accessed August 30, 2016.

8. Smart RC. Maladministrations in nuclear medicine. Radiat Prot Australasia. 2002;19:13-19.

9. Yenson T, Larcos G, Collins LT. Radiopharmaceutical maladministrations in New South Wales. Nucl Med Commun. 2005;26:1037-1041.

10. Larcos GS, Collins LT, Georgiou A, Westbrook JI. Maladministrations in nuclear medicine: revelations from the Australian Radiation Incident Register. Med J Aust. 2014;200:37-40.

11. World Alliance for Patient Safety. WHO draft guidelines for adverse event reporting and learning systems: from information to action. National Institutes of Health Office of Science Policy website. http://osp.od.nih.gov/sites/default/files/resources/ Reporting_Guidelines.pdf. Published 2005. Accessed August 30, 2016.

12. Australian radiation incident register: summary of radiation incidents-1 January 2012 to 31 December 2012. Australian Radiation Protection and Nuclear Safety
Agency website. http://www.arpansa.gov.au/pubs/RadiationProtection/arir/arir2012. pdf. Accessed August 30, 2016.

13. Australian radiation incident register: summary of radiation incidents -1 January 2013 to 31 December 2013. Australian Radiation Protection and Nuclear Safety Agency website. http://www.arpansa.gov.au/pubs/RadiationProtection/arir/arir2013. pdf. Accessed August 30, 2016.

14. Radiation Advisory Council publications. NSW Environment Protection Authority website. http://www.epa.nsw.gov.au/radiation/radiationpubs.htm. Accessed August 30, 2016.

15. Annual reports to the minister for health. Government of Western Australia Radiological Council website. http://www.radiologicalcouncil.wa.gov.au. Accessed August 30, 2016.

16. Annual reports. Victoria Department of Health website. http://www2.health.vic. gov.au/about/publications/annualreports. Accessed August 30, 2016.

17. Data and Publications. South Australia Environment Protection Authority website. http://www.epa.sa.gov.au/data_and_publications. Accessed August 30, 2016.

18. Annual reports. Tasmanian Government Department of Health and Human Services website. http://www.dhhs.tas.gov.au/publichealth/radiation/publications2/ reports. Accessed August 30, 2016.

19. Ensuring correct patient, correct site, correct procedure in nuclear medicine. Australian Commission on Safety and Quality in Health Care website. http:// www.safetyandquality.gov.au/wp-content/uploads/2012/02/Protocol_NuclearMedicine.pdf. Accessed August 30, 2016.

20. Martin CJ. A survey of incidents in radiology and nuclear medicine in the west of Scotland. Br J Radiol. 2005;78:913-921.

21. Luscombe MD, Owens BD, Burke D. Weight estimation in paediatrics: a comparison of the APLS formula and the formula 'weight=3(age)+7.' Emerg Med J. 2011;28:590-593.

22. Dosage card. European Association of Nuclear Medicine website. http://www. eanm.org/docs/EANM_Dosage_Card_040214.pdf. Accessed March 3, 2016.

23. Procedure standards. Society of Nuclear Medicine and Molecular Imaging website. http://www.snmmi.org/ClinicalPractice/content.aspx?ItemNumber $=6414$. Accessed August 30, 2016.

24. Ensuring correct patient, correct site, correct procedure in nuclear medicine: frequently asked questions. Australian Commission on Safety and Quality in Health Care website. http://www.safetyandquality.gov.au/wp-content/uploads/ 2012/02/FAQ_NuclearMedicine.pdf. Accessed August 30, 2016.

25. National safety and quality health service standards, September 2012. Australian Commission on Safety and Quality in Health Care website. http://www.safetyandquality.gov. au/wp-content/uploads/2011/09/NSQHS-Standards-Sept-2012.pdf. Accessed August $30,2016$.

26. Danaher LA, Howells J, Holmes P, Scally P. Is it possible to eliminate patient identification errors in medical imaging? J Am Coll Radiol. 2011;8:568-574.

27. McCambridge J, Witton J, Elbourne DR. Systematic review of the Hawthorne effect: new concepts are needed to study research participation effects. J Clin Epidemiol. 2014;67:267-277.

28. Larcos G, Collins LT, Georgiou A, Westbrook JI. Nuclear medicine incident reporting in Australia: control charts and notification rates inform quality improvement-control charts for nuclear medicine. Intern Med J. 2015;45:609-617.

29. Evans SM, Berry JG, Smith BJ, et al. Attitudes and barriers to incident reporting: a collaborative hospital study. Qual Saf Health Care. 2006;15:39-43.

30. Donnelly LF, Dickerson JM, Goodfriend MA, Muething SE. Improving patient safety in radiology. AJR. 2010;194:1183-1187.

31. Kalra J. Medical errors: an introduction to concepts. Clin Biochem. 2004;37:10431051. 